\title{
Mediational Role of Customer Emotions in the Relationship Between Customer Experience and Purchase Behavior in the Hotel Industry
}

\author{
Beatrice Chepngetich ${ }^{1} \quad$ Oscar Kambona Ouma ${ }^{1} \quad$ Fredrick Onyango Aila ${ }^{2}$ \\ 1.Department of Ecotourism, Hotel and Institution Management, Maseno University, P.O Box Private bag, \\ Maseno, Kenya \\ 2.Department of Business Administration, Maseno University, P.O Box Private bag, Maseno, Kenya
}

\begin{abstract}
Consumers experience a broad range of emotions, both simultaneously and successively while interacting with service providers. The role and effect of emotion are drawing greater attention from marketing intellectuals in their quest for a better understanding of consumers and their consumption experiences. This study aimed at assessing customer experience and its relative effects on customer emotions and purchase behavior in the Kenyan hotel industry. The study adopted Berry and Carbone's conceptualization of customer experience; Ritchins' (1997) clues to measure customer emotions and Shen and Zhao (2005) indicators to measure purchase behavior. A mixed exploratory research design was adopted to conduct the research where self administered questionnaires were used to collect quantitative data. The study assessed luxury hotels within Nairobi (20), Kisumu (1) and Mombasa (10) since they had a clear and consistent organizational structure and can give more insight into experiences because of their experienced and demanding clientele. The study population was 5,800 guests staying in the hotels. A total of 361 guests were selected as the sample size using multi stage sampling procedure. Data was analyzed using descriptive statistics which involved use of means, percentages and tests for normality and inferential statistics which included the use of correlation, principal axis factor analysis, regression and bootstrapping. Regression results showed that of the three customer experience factors, only humanic clue factor had significant influence on purchase behaviour $(\beta=.17, \mathrm{t}=1.94, \mathrm{p}=.05)$, with the rest of the two factors having no significant influence. The three customer experience factors together with customer emotions account for $44 \%$ of the total variance explained in purchase behaviour. Mediation results showed that customer emotions (CE) fully mediates the relationship between Functional clues factor (FCF) and purchase behaviour (PB) $(\beta=.08, \mathrm{t}=1.97, \mathrm{p}=.05, \mathrm{VAF}=200 \%)$. Customer emotions (CE) partially mediates the relationship between Humanic clues factor (HCF) and purchase behaviour $(\mathrm{PB})(\beta=.14, \mathrm{t}=3.24, \mathrm{p}=.00, \mathrm{VAF}=45 \%)$ and the relationship between Mechanic clues factor (MCF) and purchase behaviour $(\mathrm{PB})(\beta=.11, \mathrm{t}=2.21, \mathrm{p}=.03, \mathrm{VAF}=50 \%)$. The study findings complement the existing literature regarding the role of emotions in service settings and offer a new point of view for the linkage among customer emotions, customer experience drivers and customer purchase behavior. The study findings emphasized that hotel operators must consider the impact of customers' emotions on post-purchasing behaviors in developing better marketing and service strategies for retaining customers.
\end{abstract}

Keywords: Customer, Customer experience, Customer emotions, Purchase behavior.

DOI: $10.7176 / \mathrm{JMCR} / 58-05$

Publication date:July $31^{\text {st }} 2019$

\section{Background of the Study}

Consumers experience a broad range of emotions, both simultaneously and successively while interacting with service providers (Maguire and Geiger, 2015). Customers seek experiences that would bond them emotionally to the brand and reflect that in their behaviours. Friman (2004) discovered that the degree of experiencing critical incidents did create impact on emotional reactions. LeDoux (1996) described emotional experience as how a company is able to create emotions and how it can be explained based on response, central, cognitive, and arousal theories. Thus, it is imperative for marketing professionals to understand the influence of consumption emotions on attitude change and how it influences repeat purchase. Consequently, customer experiences constitute a crucial factor that influences the customers' willingness to repeat the experience or to recommend it to friends or colleagues. Research emphasizes that customer experiences that influence a person emotionally are of a special kind because they have a tendency to be stored especially well in memory. Experiences of this nature leave, as Johnston and Clark (2001) term, "mental imprints," which accurately emphasizes the close link of these types of experiences to the arousal of emotions. Since services are intangible, the role of experience may be very prominent in attitude development. Experiences create emotions, exploring the emotions felt during and after the experience might offer clues on how to design products and services to facilitate positive experiences. The role and effect of emotion are drawing greater attention from marketing intellectuals in their quest for a better understanding of consumers and their consumption experiences (Mattila and Enz, 2002; Ladhari, 2007). Despite significant advances in loyalty research, scarce empirical work can be found on mediational role of customer emotions in the 
relationship between customer experience and purchase behaviour. . Little is known about the affective or emotional aspects of loyalty (Taylor et al., 2006), which is surprising because researchers have recognized a high degree of emotionality to loyalty (Yu and Dean, 2001; Vogel et al., 2008), but the customers' emotional responses to the relationship between customer experiences and purchase intentions have been largely ignored. Therefore, the current study aims to fill the potential gaps in the existing literature by trying to explain the mediational role of emotions.

\section{Research Methodology}

This chapter presents brief description of the research methodology that was used for the study. It covers the research design, target population, sample size, sampling procedure, data collection instrument and procedures, data analysis and presentation. The research was based on qualitative and quantitative methods. The primary data were collected from customers staying in luxury hotels. The questionnaires were with easy design and were distributed among customers present at the time of data collection in the hotels. The secondary data were collected from the journal articles and books used in the literature review.

\subsection{Research Design}

The study adopted a mixed exploratory research design where both quantitative and qualitative data was collected and analyzed. The exploratory research design was adopted as it is considered important in collecting and analyzing diverse types of data to best provide an understanding of the research problem and achieve the research objectives (Creswell, 2003). In this approach the quantitative data was accorded more priority and qualitative data was used as a justification. The design involved administering questionnaires to hotel managers in the selected hotels during the quantitative phase of the study. Quantitative data gathered was analyzed using quantitative methods in SPSS.

\subsection{Target Population}

Luxury hotels located in the three cities; Nairobi, Mombasa and Kisumu in Kenya were the unit of analysis for this study. A list of these hotels was compiled by the researcher. Only 31 hotels complied with the criteria set by the researcher for classification as a luxury hotel. A luxury hotel referred to a hotel that offers sophisticated and personalized service to its guests. These hotels should have luxurious décor and elegant ambience, superior facilities and amenities, bed capacity of 120 and above, suites, lounges and a wide range of recreational facilities. The hotels were selected for the study because they had a clear and consistent organizational structure which implied that the results can be generalized without a lot of errors. Luxury hotels were also regarded as an ideal domain to study experiences. These luxury hotels gave more insight into experiences because of their experienced and demanding clientele, as well as importance given on product and service design. The study population consisted of 5800 guests who were staying in the selected hotels within a period of four weeks.

\subsection{Sample Size and Sampling Procedures}

The study adopted a multi stage sampling procedure considering vastness of the study area. Multi stage sampling is a sampling procedure that involves use of more than one sampling procedure in selecting participant of the survey in stages. Sampling procedure to determine sample size for the study was conducted. Empirical analysis was based on a sampling frame that consisted of luxury hotels located in Nairobi, Mombasa and Kisumu. Purposive sampling was used to identify hotels that gave the needed information. Two dimensions were used to select the hotels; amenities and bed capacity. The guests to participate in the study were determined using Cochran's formula which gave a sample size of 361 guests. Israel (1992) recommended the use of Cochran's formula in calculating the sample size when the population is huge and can change at any time of the study. The total number of guests to participate in the study in each hotel was selected using proportionate sampling. This implied that the number of rooms in each hotel was considered in relation to the total number of rooms in all the luxury hotels and total guests sample size. Guests who participated in the study were selected using systematic sampling procedure such that every guest staying in the nth room was involved in each hotel.

\subsection{Measurement of Variables}

Berry and Carbone's Model (2007) was used for measuring customer experience. This model posited that customer experience clues generally fall into three main categories: functional, mechanic and humanic. Ritchins' (1997) emotion indicators were adopted to represent respondents' consumption based emotional reactions to a recent hotel stay. Ritchins (1997) proposed three versions of the CES. The first version covers 16 identifiable clusters comprising 43 descriptors. Another version includes the 16 identifiable clusters as well as an "other items" category. In the third version, Ritchins added nine more descriptors to the first two versions. Results of six studies using several scaling procedures were used to derive the final versions of the CES. Ritchins (1997) determined the difference of consumption emotion from other kinds of emotions experienced during other types of activities and 
developed a scale, the Consumption Emotion Set (CES), to measure consumption emotions. Although CES has some limitations, Ritchins (1997) empirical test supported that CES is the most comprehensive measure in assessing consumption-related emotions. As Ritchins (1997) noted that "for some contexts, theory or common sense may suggest that certain emotions are unlikely to be experienced; in these cases, the researcher may choose to omit the descriptors for those emotions from their measuring instrument. Thus, using the entirety of CES was not necessary. Choosing emotion descriptors through the appropriate procedure, which are likely to be experienced by customers during their hotel stay, is needed for the study of emotions in the hotel industry. In this study, Ritchins (1997) empirical test was contextualized in terms of happiness, pleasure, amazement, contentment, loneliness, excitement and relaxation. Four scale items, adopted from Shen and Zhao (2005) were used to measure purchase behavioral intentions. The items are "I am willing to visit the hotel again.", "I will resist the offers of other hotels.", "I will always recommend this hotel whenever anyone seeks my advice" and "I would say positive things about this hotel to others." All items were measured on a likert scale ranging from '1' Strongly Disagree to '5' Strongly Agree.

\subsection{Data Collection Methods}

Self-administered questionnaires were used to collect data. Self-administered questionnaires were considered because the respondents answered at their own convenient time. Questionnaires were chosen because administration of questionnaires to individuals helped to establish relationships with the respondents while introducing the survey (Satirenjit et. al., 2012). Questionnaires provided the clarifications sought by respondents and they may even be collected immediately after they are completed.

\subsection{Data Pollection Procedures}

The data collection procedures involved getting the authority letter from the University to facilitate data collection process. Letter of introduction was sent to the selected hotels notifying the managers of the intention to conduct research in the hotels. This paved way for accessibility to the hotels. The questionnaires to be administered were then delivered to the receptionists in each of the selected hotels. The questionnaires were distributed to those guests checking in to the selected rooms by the receptionist during the four weeks data collection period. Guests were instructed to fill the first part of the questionnaire on check in and the other parts upon their departure.

\subsection{Data Analysis}

Data collected was analyzed using both descriptive and inferential statistics. Means, percentages and tests for normality was used to describe the data. Correlation was also used to examine the relationship between customer experience and customer behavior variables. Regression analysis was used to determine the dependence of customer emotions on customer experiences. Bootstrapping procedure in SmartPLS 3.2.7 was used to establish the mediational effect of customer emotions on customer behavior. To determine the type of mediation, ratios of specific indirect effect to total effect were computed.

\subsection{Ethical Considerations}

A research permit was obtained from Maseno University Ethics Review Committee (MUERC) to conduct research in the area of study. Access permission was also obtained from the various selected hotels through a letter of introduction. The researcher ensured voluntary participation by ensuring that the participants understood that their participation was voluntary and that there were no consequences for refusing to participate in the study or to answer specific questions. The consent of the respondents was obtained prior to administration of the questionnaire. Respondents were guaranteed anonymity and assured that their responses were used for purposes of the study only. Confidentiality was ensured by keeping personal information that were revealed confidential and ensuring that no information was identified to a particular study participant. All the information gained from the respondent was treated with confidentiality. The name of the respondent was not included in the study and the data files obtained were kept in lockable cabinets and once it was processed, the data was secured by a password. Respect for other peoples' rights, dignity and diversity will be upheld which include respect for others to hold values, attitudes and opinions that differ from those of the researcher. The respondents were free to stop the filling of the questionnaire or the key informant interviews whenever they felt that they were uncomfortable with the contents in the data collection tools. There were no direct benefits to the respondents however, the results generated from this study will be shared with the various hotel management that participated in this study.

\section{Results and Findings}

This chapter looks at questionnaire response, reliability and validity tests; respondents profile and results based on factor, regression analysis and bootsrapping. 


\subsection{Questionnaire Response}

The target respondents for this research were predominantly guests staying in the selected hotels within the four weeks data collection period. A total of 361 questionnaires were distributed in the selected hotels. The number of responses achieved was 321 providing a response rate of $88.92 \%$. The reason for the low response rate was not only due to the timing of the survey distribution, which was a non-peak time of year for hotels, but also some of the respondents went with the questionnaires and it was difficult to follow up.

\subsection{Validity and Reliability Tests of the Research Instruments}

In order to conduct factor and regression analysis the variables in the research model were tested for their validity and reliability. Questionnaires were tested for content validity to establish quality of instrument. These procedures involved pilot testing conducted on $10 \%$ of the total sample which was then excluded from the study. There was no variation from the expected result and the instrument was considered to be valid. Piloting was also used to identify the length of time it will take to fill questionnaires, check understanding of the tool and correct simple mistakes like spelling and wording of sentences. The pilot study was done as if it was a normal survey and data generated was used to do a reliability test based on Cronbach's alpha of the items in the instruments. The reliability of the measures was established by testing for consistency and stability of the questionnaire results in the pre-test study and the main survey using Cronbach's alpha. Cronbach's alpha is a reliability coefficient that indicates how well the items in a set are positively correlated to one another. The Cronbach alpha coefficient was computed for all the construct measures in SPSS 21 to ascertain the reliability for all the sets of measures. Reliability tests were done for all the sets of measures i.e. customer experience and purchase behavior. George and Mallery (2003) rules of thumb was used to classify the Cronbach's alpha coefficients generated. These rules of thumb provide the following: " $>.9-$ Excellent, $>.8-$ Good, $>.7$ - Acceptable, $>.6-$ Questionable, $>.5-$ Poor, and $<.5-$ Unacceptable" (p. 231). The closer the Cronbach's alpha is to 1.0, the higher the internal consistency reliability. During the pre-test, dimensions of customer experience measures registered excellent reliability while customer emotions and purchase behavior measures registered acceptable reliability. Cronbach's alpha reliability coefficients registered in the main survey were as follows: Customer experience measures $\alpha=.95$ and purchase behavior measures $\alpha=.74$. This shows that the items were reliable in measuring their respective constructs given that all the Cronbach's alpha for the constructs in both the pre-test and main survey were >.7.

\subsection{Descriptive Distribution for Data}

To determine the distribution of data skewness and kurtosis was used. Skewness assesses the extent to which a variable's distribution is symmetrical while Kurtosis measure whether the distribution is too peaked (Hair et al., 2014). A general guideline for skewness provides that the value should be between +2 and -2 , and if that is exceeded, then it is an indication of a substantially skewed distribution (Gravetter \& Wallnau, 2014, George \& Mallery, 2010). Likewise, kurtosis values should be between +2 and -2 for the data to be considered normal (Gravetter \& Wallnau, 2014). In particular, a kurtosis greater than +2 indicates that the distribution is too peaked while a kurtosis of less than -2 indicates a distribution that is too flat. Frequencies were first computed for each item and checks made for missing data and outlier responses by producing boxplots in SPSS 21 . The results indicated no missing data and outlier issues. On average, the data exhibited normal distribution with the skewness and kurtosis values falling in the range of -2 and +2 (see Table 1).

Table 1. Descriptive Statistics for normal distribution

\begin{tabular}{lrrrrrr}
\hline Measurement Variables & Min & Max & Mean & SD & Skewness & Kurtosis \\
\hline Employees of the hotel are courteous & 3.00 & 5.00 & 4.48 & 0.62 & -0.78 & -0.39 \\
Employees are neat and well dressed & 2.00 & 5.00 & 4.40 & 0.62 & -0.62 & -0.15 \\
Employees behaviour instils confidence in guests & 2.00 & 5.00 & 4.40 & 0.67 & -0.72 & -0.29 \\
Hotel employees are friendly & 2.00 & 5.00 & 4.36 & 0.63 & -0.54 & -0.23 \\
Employees treat their guests with respect & 2.00 & 5.00 & 4.38 & 0.63 & -0.57 & -0.21 \\
$\begin{array}{l}\text { Hotel employees shows interests in solving guests } \\
\text { problems }\end{array}$ & 1.00 & 5.00 & 4.32 & 0.73 & -1.21 & 1.98 \\
Employees of the hotel understands guests specific & & & & & & \\
needs & 2.00 & 5.00 & 4.34 & 0.67 & -0.65 & -0.11 \\
Individual attention is given by the hotel staff & 2.00 & 5.00 & 4.33 & 0.71 & -0.69 & -0.37 \\
Hotel staff care about their customers & 3.00 & 5.00 & 4.39 & 0.65 & -0.58 & -0.64 \\
Hotel staff has guests interest at heart & 1.00 & 5.00 & 4.32 & 0.70 & -0.75 & 0.49 \\
Employees of the hotel are always willing to help & 2.00 & 5.00 & 4.35 & 0.70 & -0.65 & -0.51 \\
The employees of the hotel deliver services promptly & 2.00 & 5.00 & 4.37 & 0.66 & -0.64 & -0.34 \\
Hotel employees make you feel safe during your hotel & 2.00 & 5.00 & 4.32 & 0.66 & -0.53 & -0.41 \\
stay & & & & & &
\end{tabular}




\begin{tabular}{|c|c|c|c|c|c|c|}
\hline Measurement Variables & Min & Max & Mean & SD & Skewness & Kurtosis \\
\hline $\begin{array}{l}\text { Employees have the knowledge to answer guests } \\
\text { questions }\end{array}$ & 1.00 & 5.00 & 4.45 & 0.68 & -1.56 & 4.71 \\
\hline The hotel is kept clean & 2.00 & 5.00 & 4.60 & 0.57 & -1.18 & 0.94 \\
\hline $\begin{array}{l}\text { The television in the guest room is in proper working } \\
\text { condition }\end{array}$ & 3.00 & 5.00 & 4.59 & 0.61 & -1.18 & 0.34 \\
\hline $\begin{array}{l}\text { The exterior appearance of the hotel is visually } \\
\text { appealing }\end{array}$ & 3.00 & 5.00 & 4.51 & 0.62 & -0.88 & -0.24 \\
\hline The layout of the hotel makes it easy to get around & 2.00 & 5.00 & 4.41 & 0.65 & -0.72 & -0.20 \\
\hline The arrangement of the hotel furnishing is done right & 2.00 & 5.00 & 4.45 & 0.65 & -0.81 & -0.06 \\
\hline $\begin{array}{l}\text { The physical layout of the furniture and furnishings in } \\
\text { the hotel are comfortable }\end{array}$ & 2.00 & 5.00 & 4.50 & 0.63 & -0.96 & 0.24 \\
\hline $\begin{array}{l}\text { The ambient conditions such as temperature, } \\
\text { ventilation, noise and odour of the hotel are good }\end{array}$ & 3.00 & 5.00 & 4.57 & 0.62 & -1.16 & 0.26 \\
\hline The hotel lighting is pleasant & 3.00 & 5.00 & 4.48 & 0.69 & -0.96 & -0.35 \\
\hline The background music is pleasing & 1.00 & 5.00 & 4.29 & $1 .($ & & 2.69 \\
\hline The overall hotel facility is visually appealing & 2.00 & 5.00 & 4.44 & 0.6 & -0.79 & -0.11 \\
\hline The hotel is flexible in meeting customer needs & 2.00 & 5.00 & & & & -0.17 \\
\hline The hotel delivers its services on time & 3.00 & 5.00 & 4.31 & 0.59 & & -0.61 \\
\hline The hotel has standardised product delivery process & 3.00 & 5.00 & 4.28 & 0.64 & -0.33 & -0.69 \\
\hline $\begin{array}{l}\text { The additional wi-fi services provided by the hotel are } \\
\text { valuable to you }\end{array}$ & 3.00 & 5.00 & 4.49 & 0.60 & -0.72 & -0.44 \\
\hline The hotel gives prompt responses for your queries & 2.00 & 5.00 & 4.27 & 0.70 & -0.47 & -0.64 \\
\hline $\begin{array}{l}\text { The food and drink offered in the restaurant are } \\
\text { delicious }\end{array}$ & 1.00 & 5.00 & 4.47 & 0.67 & -1.13 & 1.51 \\
\hline The food presentation is visually attractive & 2.00 & & & & & 0.17 \\
\hline has great lobby facilities & 3.00 & 5.00 & 4.39 & & & -0.63 \\
\hline nt guest rooms & 2.00 & & & & & 0.43 \\
\hline ety of food and beverage & 2.00 & 5.00 & 4.45 & 0. & & 1.39 \\
\hline ty of recreational facilities & 1.00 & & 4.24 & & & 0.97 \\
\hline rent hotel stay experience makes me feel happy & & & & & & -0.27 \\
\hline eased with my current hotel experience & 3.00 & 5.00 & 4.34 & & & -0.66 \\
\hline I am amazed with my current hotel experience & & & & & & -0.78 \\
\hline My current hotel stay experience makes me feel relaxed & 2.00 & 5.00 & 4.34 & 0.67 & -0.71 & 0.17 \\
\hline $\begin{array}{l}\text { My current hotel stay experience makes me feel } \\
\text { contented }\end{array}$ & 2.00 & 5.00 & 4.29 & 0.70 & -0.58 & -0.37 \\
\hline My current hotel stay experience makes me feel excited & 1.00 & 5.00 & 4.25 & 0.80 & -1.01 & 1.32 \\
\hline rent hotel stay experience makes me feel lonely & 1.00 & 5.00 & 2.52 & & & -1.39 \\
\hline llling to visit this hotel again & 2.00 & 5.00 & 4.52 & 0.70 & & 0.87 \\
\hline I will resist the offers of other hotels & 1.00 & 5.00 & 3.42 & 1.39 & -0.39 & -1.12 \\
\hline $\begin{array}{l}\text { I will always recommend this hotel whenever anyone } \\
\text { seek my advice }\end{array}$ & 1.00 & 5.00 & 4.09 & 0.99 & -0.77 & -0.38 \\
\hline I would say positive things about this hotel to others & 1.00 & 5.00 & 4.02 & 1.05 & -0.81 & -0.22 \\
\hline
\end{tabular}

Note: SD - Standard Deviation, Min - Minimum, Max

- Maximum Valid N (listwise) $=321$

\subsection{Mediating Effect of Customer Emotions in the Relationship between Customer Experience and Customers' Purchase Behavior}

In order to establish the mediating effect of customer emotions on the relationship between customer experience and customers' purchase behaviour in the hotel industry, the specific indirect effects results obtained using bootstrapping procedure in SmartPLS 3.2.7 were used (Hair et al., 2017; Hair et al., 2014). To determine the type of mediation, ratios of specific indirect effect to total effect were computed where by a VAF $>80 \%$ indicates full mediation, $20 \% \leq \mathrm{VAF} \geq 80 \%$ shows partial mediation while VAF $<20 \%$ assumes no mediation (Preacher \& Kelly, 2011; Hair et al., 2014). As indicated in Table 2, Customer emotions (CE) fully mediates the relationship between Functional clues factor (FCF) and purchase behaviour (PB) $(\beta=.08, t=1.97, p=.05, \mathrm{VAF}=200 \%)$. Customer emotions (CE) partially mediates the relationship between Humanic clues factor (HCF) and purchase behaviour $(\mathrm{PB})(\beta=.14, \mathrm{t}=3.24, \mathrm{p}=.00, \mathrm{VAF}=45 \%)$ and the relationship between Mechanic clues factor $(\mathrm{MCF})$ and purchase behaviour $(\mathrm{PB})(\beta=.11, \mathrm{t}=2.21, \mathrm{p}=.03, \mathrm{VAF}=50 \%)$. The results of the study reveal that customer emotions appear to be a full mediator in the relationship between functional clues factor and purchase intentions. 
Customer emotions fully mediates the relationship between functional clues factor and purchase intentions which means, to keep customers hotel industries should have to stimulate customer emotions by providing functional experiential elements such as great lobby facilities, prompt response to queries and excellent guestrooms. Customer emotions partially mediate the relationship between humanic clues factor and mechanic clues factor. Customer emotions partially mediates the relationship between humanic clue factor and purchase intentions which means to keep customers hotel industries should stimulate customer emotions by providing humanic experiential elements such as high level of friendliness, guest respect and understanding of guest needs by employees. Finally customer emotions partially mediates the relationship between mechanic clue factor and purchase intentions which means to keep customers hotel industries should stimulate customer emotions by providing mechanic experiential elements such as excellent hotel layout, appealing exterior appearance and proper functioning of hotel equipment. Table 2. Test of mediation by bootstrapping

\begin{tabular}{|c|c|c|c|c|c|c|c|c|c|c|c|c|c|c|}
\hline \multirow[b]{2}{*}{ Path } & \multicolumn{4}{|c|}{ Specific indirect effect } & \multicolumn{4}{|c|}{ Total effect } & \multicolumn{4}{|c|}{ Total indirect effect } & \multirow[b]{2}{*}{ VAF } & \multirow[b]{2}{*}{ Mediation } \\
\hline & $\beta$ & t-value & $\mathbf{p}$ & Sig. & $\beta$ & t-value & $\mathbf{p}$ & Sig. & $\boldsymbol{\beta}$ & t-value & $\mathbf{p}$ & Sig. & & \\
\hline $\mathrm{FCF}>\mathrm{CE}>\mathrm{PB}$ & 0.08 & 1.97 & $\begin{array}{r}0.0 \\
5\end{array}$ & $*$ & 0.04 & 0.40 & 0.69 & NS & 0.08 & 1.97 & 0.05 & * & 2.00 & Full \\
\hline $\mathrm{HCF}>\mathrm{CE}>\mathrm{PB}$ & 0.14 & 3.24 & $\begin{array}{r}0.0 \\
0\end{array}$ & $* * * *$ & 0.31 & 3.89 & 0.00 & $* * *$ & 0.14 & 3.24 & 0.00 & $* * *$ & 0.45 & Partial \\
\hline $\mathrm{MCF}>\mathrm{CE}>\mathrm{PB}$ & 0.11 & 2.21 & $\begin{array}{r}0.0 \\
3\end{array}$ & *** & 0.22 & 2.20 & 0.03 & $* * * *$ & 0.11 & 2.21 & 0.03 & $* *$ & 0.50 & Partial \\
\hline
\end{tabular}

Note: VAF - variance accounted for. VAF computed as a ratio between specific indirect effects and total indirect effects.

VAF $>80 \%$ indicates full mediation, $20 \% \leq \mathrm{VAF} \geq 80 \%$ shows partial mediation while VAF $<20 \%$ assumes no mediation;

FCF-Functional clues factor, $\mathrm{CE}-\mathrm{Customer}$ emotions, HCF-Humanic clues factor, MCF-Mechanic clues factor, PB-Purchase behaviour; $p-p$ value, $\beta$ - beta coefficient, Sig.- Significance level, NS - Not significant.

$* \mathrm{p}<.05 . * * \mathrm{p}<.01, * * * \mathrm{p}<.001$.

\section{Discussions}

The study findings reveal that customer emotional responses will enhance or lessen their consumption experiences that ultimately influence purchase intentions. Purchase intentions is driven by emotions in the hospitality and tourism industry. Thus, in order to better predict customer purchase intentions, the emotional component is crucial and should be included along with other cognitive components. The findings of this study complement the existing literature regarding the role of emotions in service settings and offer a new point of view for the linkage among emotions, customer experience clues and customer purchase intentions. This is in line with other researchers findings who pointed out that emotions significantly contribute to the selection of service providers, evaluation of service quality, determination of repeat purchasing behaviors, development of brand loyalty and directly influence behavioral intentions (Mattila and Enz, 2002; Jaiswal and Niraj, 2011; Bigdeli and Bigdeli, 2014; Ali and Amin, 2014; Palau-Saumell et al., 2014; Tsaur et al., 2015). It also agrees with a number of studies that suggested that customer emotions create significant impact in formatting and modifying approaches used by consumers to consume products and services (Hoyer and McInnis, 2001; Price, Arnould and Tierney, 1995). This suggests that the degree of experiencing critical incidents did create impact on emotional reactions of the guests which finally dictates their purchase behavior (Friman, 2004). The findings also corroborate with Allen, Machleit, and Klein (1992) findings that consumers' purchases are strongly influenced by their emotions, and consumption emotions influence both satisfaction and repeat patronage.

\section{Theoretical Contribution}

The study considers the mediational role of customer emotions in the relationship between customer experience and purchase behaviour. The empirical findings support a number of studies (Bloomer et al., 1999; Mano, 1999; Menon \& Kahn, 2002; Bitner, 1992; Smith \& Bolton, 2002; Helm \& Mark, 2012) who have examined the moderating impact of emotions in the relationship between the dimensions of customer experience and purchase behaviour in service settings. The study revealed that customer experience appears to be a full mediator in the relationship between functional clue factor and purchase behaviour but a partial mediator in the relationship among humanic clue factor, mechanic clue and purchase behaviour. This is an important contribution since most previous studies have reported the direct effects of emotions on purchase intentions (Ladhari, 2007). More recently, findings of Bilgihan et al. (2016) bring into consideration the key role of emotions in services and emphasize that in service context, firms need to pay more attention to customer emotions in order to improve customer loyalty. But this 
study uniquely contributes to explain the influence of emotions on the effectiveness of marketing strategies by examining the moderating effect of emotions. This finding complements the existing literature regarding the role of emotions in service settings and offers a new point of view for the linkage among customer emotions, customer experience dimensions and customers purchase behaviours. These findings further reveal that customer emotions should be continuously monitored during the service delivery process. Since customers' emotional responses throughout service delivery are strongly linked to purchase behaviour, service managers need to make sure that service encounters should evoke positive emotional feelings to the customers.

\section{Practical Implications}

The study presents the role of customer emotions in the relationship between customer experience drivers and purchase behaviour, this research demonstrate that emotions are intrinsic and vital to the rational decision-making process. Since customers' emotional responses throughout service delivery are strongly linked to purchase behavior, therefore hotel managers need to make sure that the customers experience with their services as pleasurable as possible and for this purpose, customer service employees need to be trained in order to better understand the customers' emotional responses during the course of service delivery process. This suggest that hotel industries should not ignore the emotions experienced by consumers and paying attention to consumers' emotions may result in better decision-making process and help managers in devising marketing strategies accordingly.

\section{References}

Ali, F. and Amin, M. (2014). The influence of physical environment on emotions, customer satisfaction and behavioral intentions in Chinese resort hotel industry. Journal for Global Business Advancement, 7(3), 249266.

Allen, C.T., Machleit, K.A. and Kleine, S.S. (1992). A comparison of attitudes and emotions as predictors of behavior at diverse levels of behavioral experience. Journal of Consumer Research, 18(4), 493-504.

Berry, L. L., \& Carbone, L. P., (2007). Build Loyalty through Experience Management, Quality Progress, 40(9), 26-32.

Bigdeli, F. and Bigdeli, A. (2014). The influence of atmospheric elements on emotions, perceived value and behavioral intentions. Management Science Letters, 4(5), 859-870.

Bilgihan, A., Madanoglu, M. and Ricci, P. (2016). Service attributes as drivers of behavioral loyalty in casinos: the mediating effect of attitudinal loyalty. Journal of Retailing and Consumer Services, 31, 14-21.

Bitner, M.J. (1992). Servicescapes: the impact of physical surroundings on customers and employees. The Journal of Marketing, 56, 57-71.

Bloemer, J., De Ruyter, K. and Wetzels, M. (1999). Linking perceived service quality and service loyalty: a multidimensional perspective. European Journal of Marketing, 33, 1082-1106.

Creswell, J. (2003). Educational Research: Planning, Conducting, and Evaluating Quantitative and Qualitative Research. Merrill Prentice Hall:Upper Saddle River, NJ.

Friman, M. (2004). The structure of affective reactions to critical incidents. Journal of Economic Psychology, 25, 331-353.

George, D., \& Mallery, M. (2010). SPSS for Windows Step by Step: A Simple Guide and Reference, 17.0 update ( $10^{\text {th }}$ ed.) Boston: Pearson.

Gravetter, F. and Wallnau, L. (2014) Essentials of Statistics for the Behavioral Sciences (8th Ed.). Wadsworth, Belmont, CA.

Hair, J. F., Hollingsworth, C. L., Randolph, A. B., \& Chong, A. Y. L. (2017). An updated and expanded assessment of PLS-SEM in information systems research. Industrial Management \& Data Systems, 117(3).

Hair, J.F., Hult, G.T., Ringle, C. M., \& Sarstedt, M. (2014). A primer on partial least squares structural equation modelling (PLS-SEM), 60-78.

Helm, R. and Mark, A. (2012). Analysis and evaluation of moderator effects in regression models: state of art, alternatives and empirical example. Review of Managerial Science, 6 (4), 307-332.

Hoyer, W. D. A., \& McInnis, D. (2001). Consumer behavior. Boston, MA: Houghton Mifflin.

Israel, Glenn D. (1992). Sampling The Evidence Of Extension Program Impact. Program Evaluation and Organizational Development, IFAS, University of Florida.

Jaiswal, A.K. and Niraj, R. (2011). Examining mediating role of attitudinal loyalty and nonlinear effects in satisfaction-behavioral intentions relationship. Journal of Services Marketing, 25(3), 165-175.

Johnston, R. \& Clark, G.(2001). Service Operations Management. Prentice-Hall, Harlow, United Kingdom.

Ladhari, R. (2007). The effect of consumption emotions on satisfaction and word of mouth communications. Psychology and Marketing, 24(12), 1085-1108.

LeDoux, J. (1996). The emotional brain. New York: Simon \& Schuster.

Maguire, L. and Geiger, S. (2015). Emotional timescapes: the temporal perspective and consumption emotions in 
services. Journal of Services Marketing, 29(3), 211-223.

Mano, H. (1999). The influence of pre-existing negative affect on store purchase intentions. Journal of Retailing, 75(2), 149-172.

Mattila, A.S. and Enz, C.A. (2002). The role of emotions in service encounters. Journal of Service Research, 4(4), 268-277.

Menon, S. and Kahn, B. (2002). Cross-category effects of induced arousal and pleasure on the internet shopping experience. Journal of Retailing, 78(1), 31-40.

Preacher, K. J., \& Kelly, K. (2011). Effect size measures for mediation models: Quantitative strategies for communicating indirect effects. Psychological Methods, 16, 95-115.

Price, L., Arnould, E., \& Tierney, P. (1995). Going to extremes: Managing service experiences and assessing provider performance. Journal of Marketing, 59(2), 83-97.

Palau-Saumell, R., Forgas-Coll, S., Sánchez-García, J. and Prats-Planagumà, L. (2014). Managing dive centres: SCUBA divers' behavioural intentions. European Sport Management Quarterly, 14(4), 422-443.

Richins, M.L. (1997). Measuring emotions in the consumption experience. Journal of Consumer Research, 24(2), $127-146$

Satrirenjit, J., Alistair, B. \& Martin, B. (2012). A Study on the use of mixed method approach via sequential procedure to investigate corporate governance in corporate entrepreneurship among the 100 UK financial times stock exchange companies. African Journal of Business Management. 6(21), 6369-6377.

Shen Y, Zhao P (2005). A Comparative Research on Consumer Complaint Behavior. Acta Psychologica Sinica, 37(3), 397-402.

Smith, A.K. and Bolton, R.N. (2002). The effect of customers' emotional responses to service failures on their recovery effort evaluations and satisfaction judgments. Journal of the Academy of Marketing Science, 30(1), $5-23$.

Tsaur, S.H., Luoh, H.F. and Syue, S.S. (2015). Positive emotions and behavioral intentions of customers in fullservice restaurants: does aesthetic labor matter? International Journal of Hospitality Management, 51, 115126.

Vogel, V., Evanschitzky, H. and Ramaseshan, B. (2008). Customer equity drivers and future sales. Journal of Marketing, 72(6), 98-108.

Yu, Y.-T. \& Dean, A. (2001). The contribution of emotional satisfaction to consumer loyalty. International Journal of Service Industry Management, 12(3), 234-250. 